\section{Agregado de trióxido mineral en la preservación de segundo molar primario en agenesia de sucedáneo}

Preservation of primary second molar for agenesis substitute with mineral trioxide aggregate

\author{
Resumen \\ Se reporta un caso clínico de paciente femenina de 10 años de edad, a la que se le realiza una pulpectomía \\ del diente 75 con agregado de trióxido mineral (MTA) como material de obturación definitiva, con el fin \\ de preservar la pieza dentaria el mayor tiempo posible debido a la agenesia del sucedáneo. Se demostró la \\ eficacia tanto clínica como radiográfica del empleo del agregado trióxido mineral (MTA).
}

\section{Abstract}

The purpose of this article was to report a clinic case of a female patient of 10 years old, which was performed pulpectomy in the tooth 75 with Mineral Trioxide Aggregate (MTA). In this article was used as for definitive obturation the Mineral Trioxide Aggregate (MTA), in order to preserve the tooth as long as possible due to the agenesis of the substitute. The tooth was clinically asymtomatic and radiographs showed a progressive repair of the apical lesion after the use of the mineral trioxide aggregate (MTA)

\section{Introducción}

La conservación de la integridad de la dentición primaria en sus funciones óptimas hasta su periodo de exfoliación normal constituye uno de los objetivos fundamentales de la odontología pediátrica. ${ }^{1}$

La dentición decidua ejerce una influencia significativa sobre el crecimiento y desarrollo del niño tanto con relación a la salud general, como en la respiración, alimentación, fonación, armonía estética corpórea, mantenimiento de espacio para la dentición permanente y reducción de hábitos parafuncionales, debido a esto el tratamiento pulpar en la dentición primaria va adquiriendo cada vez más importancia. ${ }^{2}$

El tratamiento pulpar en dientes primarios comprende una gran variedad de opciones terapéuticas, que se deciden en función del estado de la pulpa. ${ }^{3}$

La pulpectomía es la técnica mediante la cual se remueve el tejido pulpar de un diente con el propósito de reducir la población bacteriana en la pulpa contaminada, y así obtener un conducto limpio y saneado. ${ }^{4} \mathrm{El}$ procedimiento de la pulpectomía está indicado en aquellos dientes con evidencia de inflamación crónica o necrosis en la pulpa radicular. ${ }^{5}$

Se debe tener en cuenta que las raíces de los molares temporales son frágiles y di- vergentes, y poseen conductos accesorios en la región de la furca, que parten del suelo de la cavidad pulpar, por lo que la instrumentación de estas resulta más difícil que la de los molares definitivos. ${ }^{6}$

Un objetivo para realizar tratamientos pulpares en odontopediatría es la permanencia de los dientes en la cavidad bucal el mayor tiempo posible sin patología. ${ }^{7}$ En agenesia de sucesor permanente las

Se define como agenesia a la ausencia de formación de un germen dental. ${ }^{8}$ Las agenesias dentarias son la malformación cráneo-facial más frecuente. ${ }^{9}$ La agenesia dentaria ocurre en $2 \%$ a $10 \%$ de la población (excluyendo los terceros molares, los cuales se encuentran ausentes hasta en $25 \%$ de la población). Las ausencias más frecuentes se reportan en los segundos premolares inferiores, seguidos de los incisivos laterales superiores. ${ }^{10}$

La prevalencia de anodoncia en personas del sexo femenino es del 8,4\% y en el masculino es del 6,5\%, observándose una mayor frecuencia de esta afección en la mandíbula. ${ }^{11}$ Dentro de los factores propuestos como causales de la oligodoncia se encuentran: trauma, infección durante el desarrollo dental, sobredosis de radiación, disfunción glandular, raquitismo, sífilis, sarampión durante el embarazo y disturbios intrauterinos seconsecuencias son más trascendentes.

\section{Rita Salcedo Rioja ${ }^{1}$ \\ Rosa Pari Espinoza ${ }^{2}$ \\ Rubén Rivera Salazar ${ }^{2}$ \\ Docente del Departamento Académico de Estomatología Pediátrica, Facultad de Odon- tología UNMSM. Lima-Perú. \\ Alumnos de quinto año de la Facultad de Odontología de la UNMSM.}

\section{Correspondencia:}

Rita Salcedo Rioja

Dirección: Facultad de Odontología de la UNMSM. Av. Germán Amézaga s/n. Lima Perú

Teléfono: 998672050

E-mail: ritasalcedor@hotmail.com

Palabras clave: Pulpectomía, dentición primaria, agregado de Trióxido Mineral, agenesia.

Keywords: Pulpectomy, primary teeth, mineral trioxide aggregate, agenesis

veros. ${ }^{12}$ Sin embargo, los factores más comunes asociados son evolutivos en general y hereditarios en particular. ${ }^{13}$

Los materiales usados para obturar los conductos de dientes temporales en pulpectomías son reabsorbibles, de igual manera que el proceso fisiológico normal de la raíz.

Cuando es necesario conservar un diente temporal en su posición, particularmente en agenesia del permanente sucedáneo se han usado diversos materiales de obturación como por ejemplo, la gutapercha por condensación lateral y el cemento de óxido de zinc-eugenol, así como el Agregado de Trióxido Mineral (MTA) como material de obturación no reabsorbibles en las pulpectomías. ${ }^{14} 1516$

Se ha encontrado que el MTA tiene propiedades de reparación y formación de hueso, así como de regeneración de los tejidos periodontales. Además, es un buen material de sellado apical cuando las condiciones no son óptimas, es decir, en presencia de humedad y sangre. ${ }^{17}$

No se recomienda utilizar el MTA como material de obturación en aquellos casos en que los dientes se exfolien, debido a la presencia del sucesor permanente que no será capaz de reabsorberlo. ${ }^{18}$

A continuación se presenta un caso de pulpectomía con MTA en dentición decidua. 


\section{Caso Clínico}

Un paciente de 10 años y 10 meses de edad de sexo femenino acude a la Clínica Universitaria de Odontología de la Universidad Nacional Mayor de San Marcos, el motivo de consulta es odontalgia a nivel de la pieza 75 . No refiere enfermedades sistémicas ni antecedentes médicos de interés.

La paciente ha visitado anteriormente al odontólogo realizándose sólo tratamientos de topicaciones de flúor. Presenta dentición mixta y un riesgo estomatológico moderado. Según la escala de Frankl y Wrigth, la paciente presenta un comportamiento definitivamente positivo. ${ }^{19}$

En la exploración clínica a nivel de la mucosa de dicha pieza se observa edema, eritema y fístula. La impresión clínica sugiere necrosis pulpar séptica, ${ }^{20}$. Fig. 1.

Se indicó radiografía periapical de la pieza 75 en la que se halló agenesia de la pieza 35. (Fig 2). La interpretación radio gráfica de la pieza 75 es: caries profunda con aparente compromiso pulpar e IRL a nivel de periápice y furca compatible con absceso, no se aprecia reabsorción radicular fisiológica que correspondería a la edad de la paciente. (Figuras 1 y 2).

Se estimó conveniente indicar una radiografía panorámica para verificar agenesia de más dientes ${ }^{21}$ en la que se verificó agenesia de la pieza 45. (Fig. 3).

Después de realizado el examen clínico y radiográfico se diagnosticó: absceso periapical agudo de la pieza 75 por caries dental y agenesia de las piezas 35 y 45 .

Se desconocen antecedentes familiares relacionados al diagnóstico de agenesia en el presente caso.

El procedimiento de la pulpectomía:

En la primera cita debido a que se trataba de una urgencia se procedió inmediatamente al drenaje del absceso y retiro del material necrótico de la cámara pulpar, se colocó hidróxido de calcio y se obturó provisionalmente con óxido de cinc y eugenol.

Luego, se procedió a realizar la pulpectomía en dos sesiones sin obturar los conductos hasta registrar silencio clínico:

Primera sesión

1. Se colocó anestesia infiltrativa: lidocaína al $2 \%$ con vasoconstrictor de $1 / 80000$.

2. Drenaje de absceso.

3. Aislamiento absoluto.
4. Limpieza de la cavidad con fresa redonda número 4 y cureta de dentina.

5. Apertura de la cámara pulpar.

6. Eliminar residuos pulpares necróticos.

7. Lavado de cámara y conductos.

8. Se colocó hidróxido de calcio P.A ${ }^{\oplus}$. Se utilizó este material debido que presenta las siguientes ventajas: inhibe la proliferación bacteriana y tiene un $\mathrm{pH}$ alcalino que favorece la muerte bacteriana.

9. Obturación provisoria con eugenato.

10.De acuerdo a su peso se prescribió amoxicilina de $500 \mathrm{mg}$ cada 8 horas por 5 días. $^{22}$

Segunda sesión

Después de dos semanas se procedió a realizar la segunda sesión.

1. Anestesia infiltrativa.

2. Aislamiento absoluto.

3. Retiro de la obturación provisoria.

4. Evaluación de la pieza dentaria temporal: No hubo exudado, a nivel de la mucosa la inflamación disminuyó, no presenta sensibilidad a la percusión.

5. Lavado y limpieza de los conductos.

6. Conductometría (Fig. 4)

7. Instrumentación con limas adecuadas a lo largo de los conductos.

8. Secado con conos de papel

9. Obturación de los conductos con MTA C.P.M. ${ }^{\circledR}$ Este material requiere humedad para fraguar; por lo que al dejar la mezcla en la loseta o en el papel se origina la deshidratación del material adquiriendo una textura seca por lo que la manipulación de este material fue dificultosa.

10. Restauración definitiva de la pieza resina.

\section{Radiografía control (Fig. 5).}

12.La restauración definitiva se realizó con composite fotopolimerizable. (Fig. 6).

Control clínico y radiográfico:

En el examen clínico y radiográfico de control al mes (Fig. 7) y a los seis meses se observa silencio clínico (Fig. 9) y progresivamente reducción de la imagen radiolúcida de la zona de furca (Fig. 8) al igual que en la pieza contralateral no se observa reabsorción radicular, por lo que se concluye que hasta la fecha el objetivo de la preservación de la pieza ha sido cumplido exitosamente.

\section{Discusión}

Se reporta un tratamiento de pulpectomía realizado con MTA en la pieza 75 en paciente femenina de 10 años de edad luego de seis meses de control clínico y radiográfico. Realizando los controles inmediatamente después del tratamiento, al mes y a los seis meses, comparando con el contralateral, tanto en el proceso de reabsorción cómo en la imagen radiolúcida en la zona de furca.

En la bibliografía consultada, el MTA ha sido reportado en odontopediatría en tratamientos pulpares en dentición decidua $^{23}$ y permanente joven ${ }^{24}$ el tratamiento de pulpectomía en dentición decidua es inusual puesto que se conoce que la reabsorción del material no es en la misma rapidez que la reabsorción radicular esperada para estas piezas. $^{25}$

O'Sullivan y col. reportaron un procedimiento similar, este se realizó en condiciones sépticas que fueron luego verificadas en silencio clínico radiográfico. A diferencia de aquel, en el presente caso se utilizó hidróxido de calcio como antiséptico previo al tratamiento definitivo.

El hidróxido de calcio ha sido reportado como un estimulante de la reabsorción radicular en dientes temporales, ${ }^{26}$ otros estudios lo utilizan exitosamente en tratamientos pulpares en dentición decidua, ${ }^{27}$ atribuyéndole características antisépticas importantes. ${ }^{28}$ Por lo que la contribución para la eliminación del foco séptico previo a la obturación definitiva del hidróxido de calcio es relevante.

Los parámetros para la valoración del éxito o fracaso de un tratamiento pulpar parten con el control clínico radiográfico a los seis meses, en donde se debe registrar silencio clínico y reducción de la lesión observada radiográficamente, ${ }^{29}$ asimismo la reabsorción radicular debe ser comparada con el contralateral sin lesión. Por lo que en el presente caso, a la fecha se considera satisfactoria la respuesta al tratamiento realizado.

\section{Conclusiones}

Se ha comprobado la eficacia del Agregado Trióxido Mineral (MTA) en el tratamiento pulpar. Sin descartar la contribución del hidróxido de calcio en el control de la infección crónica previo a la obturación definitiva. 


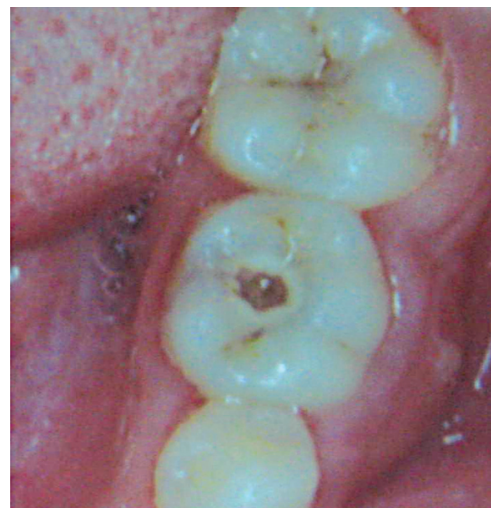

Fig. 1. Caries profunda en la pieza 75 y a nivel de la mucosa edema con fístula.

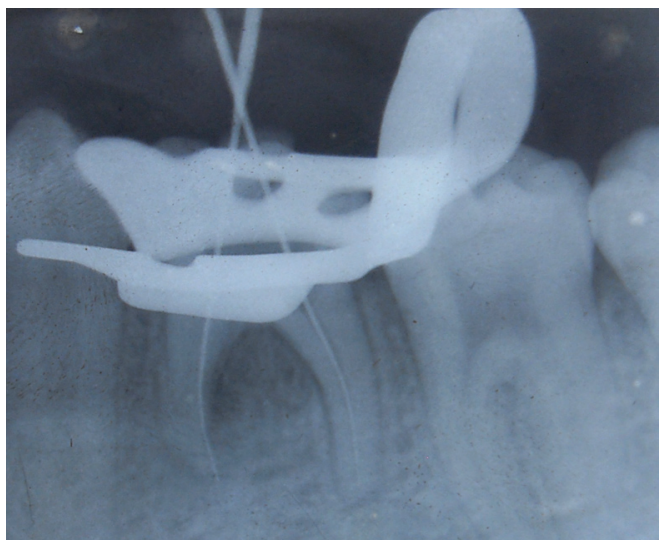

Fig. 4. Conductometría.

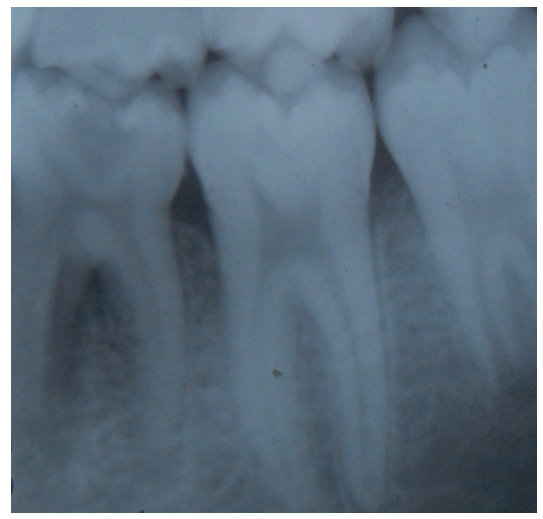

Fig. 2. Radiografía periapical de la Pza 75. Agenesia de la Pza 35

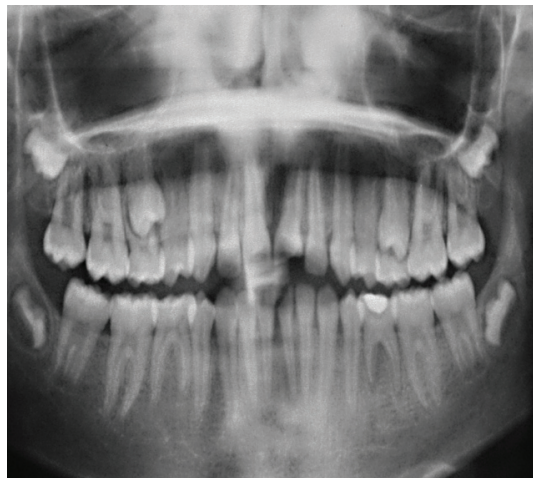

Fig. 3. Radiografía panorámica. Se observa agenesia del 35 y 45, Pza 75 después del tratamiento preoperatorio.

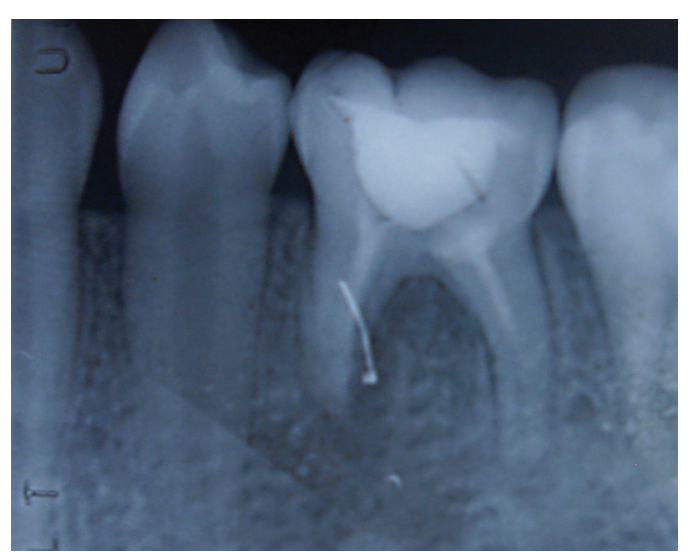

Fig. 5. Radiografía inmediata

(Se observa una línea por deterioro de la placa radiográfica).

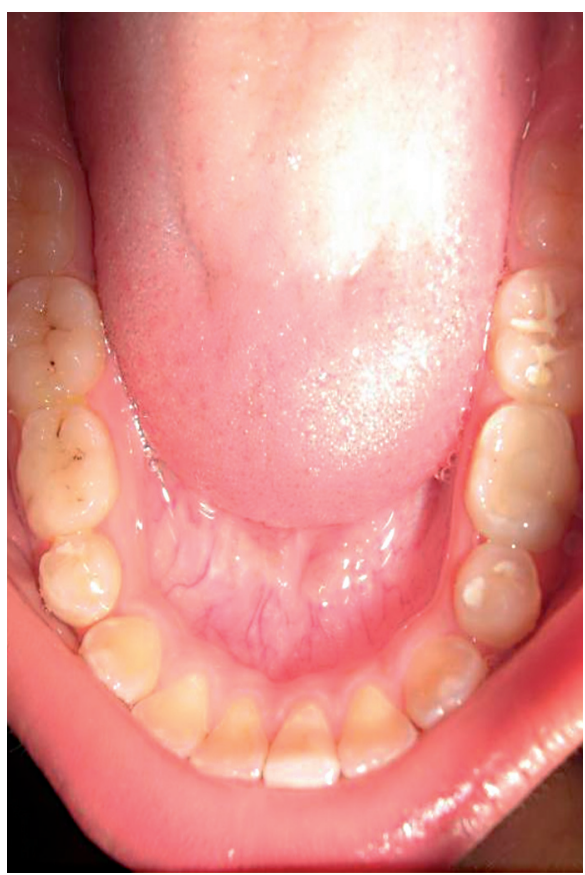

Fig. 6. Aspecto clínico post tratamiento inmediato.

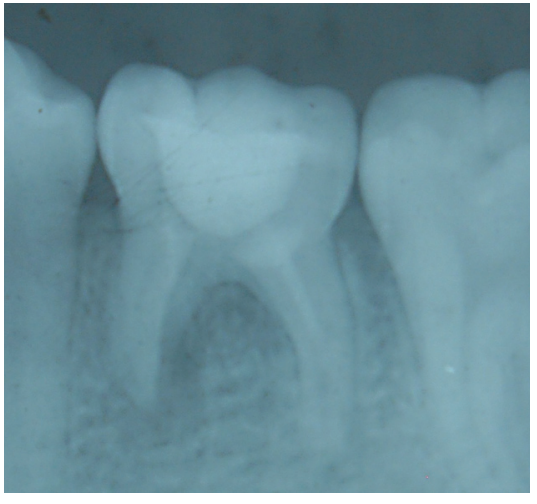

Fig. 7. Radiografía pieza 75 al mes de tratamiento.

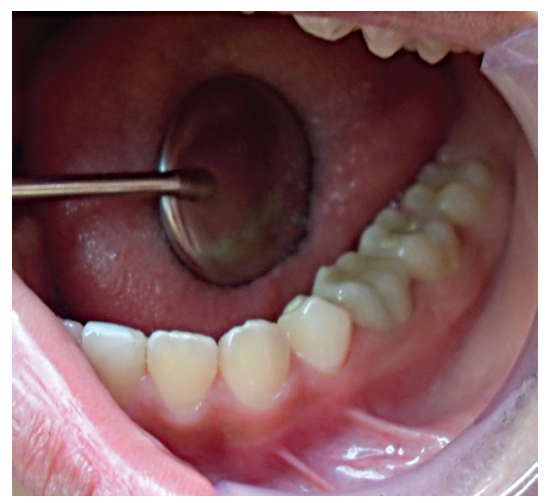

Fig. 9. Control clínico a los seis meses.

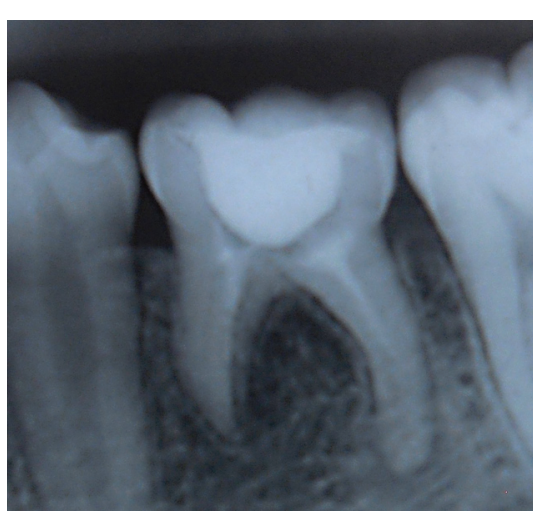

Fig. 8. Radiografía pieza 75 a los seis meses del tratamiento.

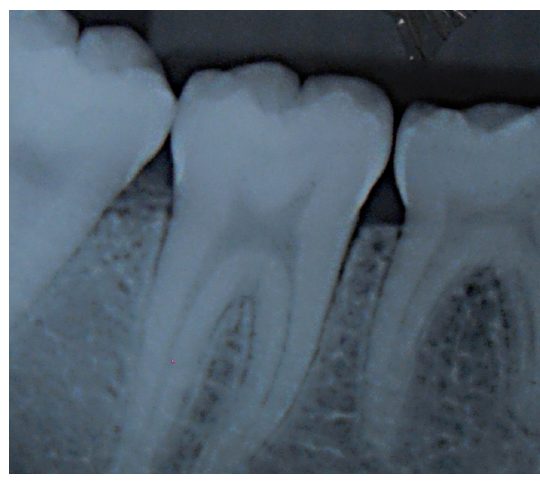

Fig. 10. Radiografía de control pieza 85 a los seis meses. 
La manipulación del MTA en pulpectomías presenta mayor dificultad que en pulpotomías.

\section{Referencias bibliográficas}

1. Boj J. Diagnóstico y tratamiento pulpar en dentición temporal. Barcelona: Editorial Masson, 2004.

2. Guedes Pinto, A. Rehabilitación oral en odontopediatría. Santa Fe de Bogotá: Editorial Amolca. 1ra edición, 2003.

3. Weisshaar S. Endodoncia en las denticiones primaria y mixta. Indicaciones, materiales y procedimientos para el tratamiento pulpar. Quintessence (ed.esp.) 2002 15(10): 371-79.

4. Boj J, Catala M, Garcia-Ballesta C, Mendoza A. Odontopediatría. Barcelona: Editorial Masson, 2004.

5. Academia Americana de Odontopediatría (AAPD). Protocolo para los tratamientos pulpares en dentición temporal. 2008.

6. Weisshaar S. Endodoncia en denticiones primaria y mixta. Fundamentos, patologías y diagnóstico. Quintessence (ed.esp.) 2003 16(7):66-74.

7. Canalda C, Brau E, Brau A. Endodoncia: Técnicas clínicas y bases científicas. España: Editorial Elsevier, 2da edición, 2006.

8. Organización Mundial de la Salud. Clasificación internacional de enfermedades aplicadas a la odontología y estomatología. tercera edición. Washington DC: OPS; 1996.

9. Kolenc F. Agenesias dentarias: en busca de las alteraciones genéticas responsables de la falta de desarrollo. Rev. Med Oral Patol Oral Cir Bucal 2004; 9(5). 385-395.

10. Mostwska A, Biedziak B, Trzeciak WH. A novel mutation in PAX9 causes familial form of molar oligodontia. Eur J Hum Genet 2006; 14(9).

11. Moret Y, González J. Anodoncia Parcial relacionada con quiste dentígero y quiste traumático. Revisión de la literatura y presentación de un caso. Rev. Odont. Venezol 2003; 14(3).

12. Zhang X, Feng H. Cases analysis and clinical classification of oligodontia: Zhonghua Kou Qiang Yi Xue Za Zhi 2003; Jul 38(4):266-8.

13. Moyers: R. Manual de Ortodoncia, 4. ${ }^{a}$ edición, Madrid: Editorial Panamericana. 1999.

14. O'Sullivan S, Hartwell G. Obturation of a retained primary mandibular second molar using mineral trioxide aggregate: a case report. J Endod 2001;27(11)703-5.

15. Cohen S, Burns R. Pathways of the pulp. 7th edition, Ed. Mosby. 1995.

16. Torabinejad M, Hong CU, Lee SJ, Monsef M, Pitt Ford TR. Investigation of mineral trioxide aggregate for root-end filling in dogs. J Endod 1995;2(12):603-608.

17. Torabinejad M, Pitt Ford TR, Mckendry DJ, Abedi HR, Miller DA, Kariyawasam SP. Histologic assessment of mineral trioxide aggregate as a root-end filling in monkeys. J Endod 1997;23(4); 225-228.

18. Torabinejad M, Higa RK, Mckendry DJ, Pitt Ford TR. Dye leakage of four root end filling materials: effects of blood contamination. J Endod 1994;20(4):159-163

19. Cárdenas J. Fundamentos de odontología pediátrica. 3era Ed. Corporación para investigaciones Biológicas. 2003.

20. López M. Etiología, clasificación y patogenia de la patología pulpar y periapical. Rev Med Oral Patol Oral Cir Bucal. 2004; 9 Suppl: 52-62.

21. Cameron A, Widmer R. Manual de odontología pediátrica. Madrid: Edit Burt Brace, 1998 .

22. Goodman \& Gilman. Las bases farmacológicas de la terapéutica. México: Editorial Mc Graw Hill. 2003

23. Bakland L. Management of traumatically injured pulps in immature teeth using. MTA. Californian Dental Association Journal 2000;28:855-858.

24. Torabinejad M, Chivian N. Aplicaciones clínicas del agregado trióxido mineral. Endodoncia 1999, 17(3):159-171.

25. Weine F. Endodontic Therapy. Madrid. 5 th. ed. Ed. Mosby. St. Louis, 1996.

26. Berman, L. Manual clínico de traumatología dental. Espańa. Editorial Elsevier.

27. Barbería E. Odontopediatría. Madrid. 2da edición, Editorial Masson. 2002.

28. Siqueira J. Lopes, H. Mechanisms of antimicrobial activity of calcium hydroxide. Int Endod J. 1999, 32: 361-69.

29. Hubertus J. Atlas de Odontología Pediátrica. España: Editorial Elsevier, 2002.

Fecha de recepción: 14 setiembre 2009

Fecha de aprobación: 5 enero 2010 